Kansas State University Libraries

New Prairie Press

\title{
EVALUATING THE EFFECT OF COMMODITY DONATION PROGRAMS USING THE TRUNCATED NORMAL DISTRIBUTION
}

J. William Levedahl

Follow this and additional works at: https://newprairiepress.org/agstatconference

Part of the Agriculture Commons, and the Applied Statistics Commons

\section{(c) (1) $\Theta(9$}

This work is licensed under a Creative Commons Attribution-Noncommercial-No Derivative Works 4.0 License.

\section{Recommended Citation}

Levedahl, J. William (1989). "EVALUATING THE EFFECT OF COMMODITY DONATION PROGRAMS USING THE TRUNCATED NORMAL DISTRIBUTION," Conference on Applied Statistics in Agriculture.

https://doi.org/10.4148/2475-7772.1464

This is brought to you for free and open access by the Conferences at New Prairie Press. It has been accepted for inclusion in Conference on Applied Statistics in Agriculture by an authorized administrator of New Prairie Press. For more information, please contact cads@k-state.edu. 


\title{
EVALUATING THE EFFECT OF COMMODITY DONATION PROGRAMS USING THE TRUNCATED NORMAL DISTRIBUTION
}

\author{
J. William Levedah $1^{*}$ \\ Economic Research Service \\ Washington, DC 20005
}

\begin{abstract}
The magnitude of both the displacement of commercial sales and the increase in consumption associated with a commodity distribution program are characterized using the truncated normal distribution. This method is easier to implement and requires less data than previous methods. It is applied to data from the 1986 Survey of TEFAP Recipients and is quite accurate.
\end{abstract}

Keywords: commodity distribution program, displacement of sales, consumption

\section{Introduction}

The impact of a commodity donation program on an existing market can be described by (1) the extent to which the donations displace commercial sales and by (2) the extent to which they increase consumption. The effects of commodity distribution programs fall on two distinct constituents. Product manufacturers bear the cost of the displaced sales while the beneficiaries of the program are consumers, chiefly low-income recipients.

The principal USDA commodity donation program is the Temporary Emergency Food Assistance Program (TEFAP). This program began in 1982 and the value of its donations reached a high of $\$ 1.03$ billion in 1984 . In all, seven commodities are donated to low income households. Donations of cheese and butter account for about 85 percent of the total value.

Previous attempts to measure the displacement of commercial cheese sales caused by TEFAP donations have employed both time series and cross sectional regression analysis (Zellner and Traub 1987, Blaylock and Blisard 1988). In addition, displacement has been estimated using The Survey of TEFAP Recipients (1986). The only evidence of TEFAP's effect on consumption has been provided by this survey.

Each method previously used to measure the impact of TEFAP has limitations. Regression analysis requires a correctly specified causal model of the cheese market no matter what type of data is used. Given the complexity of dairy product markets caused by the milk price support program such a specification is difficult to obtain.

For time series regression an additional problem is a limited number of observations. Previous studies have increased the number of observations by making the incorrect assumption that the structure of the pre and post TEFAP cheese market is the same.

Cross sectional data measures only at-home consumption. Failure to include away from home consumption means that cross section regression underestimates displacement. In addition, cross sectional results mix panel

* The view expressed herein are those of the author and not necessarily those of ERS or USDA. 
data for given geographic areas with certain causal variables such as actual TEFAP donations. These causal variables are obtained from sources other than the panel and are not necessarily associated with the households in the panel.

The Survey of TEFAP Recipients was undertaken as an alternative to regression analysis. This survey measures program response directly thereby avoiding the need to specify a casual model of the cheese market. However, a survey of the required size is costly. It is also time consuming, and thus the results may not be available when policy is made.

In this paper, a method of calculating both the displacement of commercial sales and the change in the consumption of recipients caused by a commodity distribution program is presented. The effects of the program on non-recipients, however, are not considered. It is an improvement over previous methods because it avoids the substantial data collection and modeling required by regression analysis, while it is less costly than conducting a survey and the results are more immediate.

The proposed method needs only observations on average consumption and average donation size for samples of recipients. These could be, for example, statewide averages. In this paper data from the Survey of TEFAP Recipients is used to illustrate this method. With certain sampling assumptions, the distribution of the average consumption and average donation will be normally distributed according to the central limit theorem. Properties of the truncated normal can then be used to calculated the displacement and consumption effects using this method.

\section{Displacement of Commercial Sales}

Displacement is defined as the sales that won't occur because of the donations. This definition depends on the household's prior consumption and the size of the donation received.

Displacement is associated with two types of households. The first type of household has prior consumption greater or equal to the donation it receives. In this case, displaced sales equal the donation. The second type of household receives a donation that equals or exceeds its prior consumption. In this case, the displaced sales equal the household's prior consumption.

A definition of displacement based on current consumption (that is, consumption concurrent to the program) has been used in previous studies. However, basing the definition on current consumption makes it impossible to calculate the correct displacement for households that don't purchase after receiving their donation, that is, their donation is greater than or equal to their current consumption. For these households, the value of the final units of the donated commodity is zero. At market prices these households would not consume that amount of cheese. Measuring displacement for these households using current consumption will, therefore, overstate the displacement of current sales. The correct level of displacement for these households is an unobserved level greater than prior consumption but less than current consumption. 


\subsection{Households with Donations Less than Their Prior Consumption:} Type 1 Displacement

For a group of program eligible households, let $\mathrm{T}$ denote the average donation received and $C_{o}$ the average consumption prior to the start of the program. Define the surplus $\mathrm{S}=\mathrm{T}-\mathrm{C}_{\mathrm{O}}$ as the extent to which the average donations exceeds the average prior consumption. The available data is assumed to consists of observations on $(S, T)$ defined, for example, over distinct geographical regions. Each observation is assumed to be calculated from independent drawings of the underlying household population. Therefore, the limiting distribution of $(S, T)$ is a standard bivariate normal according to the central limit theorem.

Define the standardized random variables $t=\left(T-\mu_{t}\right) / \sigma_{t}$ and $s=\left(S-\mu_{S}\right) / \sigma_{S}$ where $\mu_{t}, \sigma_{t}$ and $\mu_{s}, \sigma_{s}$ are the mean and standard deviation of $T$ and $S$, respectively. Denote the correlation coefficient as $\rho_{\text {ts }}$.

Type 1 displacement occurs in a region were there is positive average donations that are smaller or equal to average prior consumption. The set of these observations are defined by $R(s, t)=\left\{t>-\mu_{t} / \sigma_{t}, s \leq-\mu_{s} / \sigma_{s}\right\}$ since $T>0$ implies $t>-\mu_{t} / \sigma_{t}$, and $s \leq 0$ implies $s \leq-\mu_{s} / \sigma_{s}$. Results from Rosenbaum (1961) on the distribution of truncated bivariate normal random variables are used to calculate the average donation for type 1 households.

Specifically, the mean donation for the regions satisfying the type 1 criteria is,

$$
F \cdot E\left(t \mid t>-\mu_{t} / \sigma_{t}, \quad s \leq-\mu_{S} / \sigma_{S}\right)=\phi(h) \Phi\left(k^{*}\right)-\rho_{t S} \phi(k)\left(1-\Phi\left(h^{*}\right)\right)
$$

where $F=\operatorname{Prob}\left(t>-\mu_{t} / \sigma_{t}, s \leq-\mu_{s} / \sigma_{s}\right), \phi$ and $\Phi$ denote the standard normal density function and the cumulative distribution function respectively, and

$$
\begin{aligned}
& \mathrm{h}=-\mu_{t} / \sigma_{t}, \\
& \mathrm{~h}^{*}=\left(-\mu_{t} / \sigma_{t}+\rho_{t s} \mu_{s} / \sigma_{s}\right) /\left(1-\rho^{2}\right)^{1 / 2}, \\
& \mathrm{k}=-\mu_{\mathrm{s}} / \sigma_{\mathrm{s}}, \\
& \mathrm{k}^{*}=\left(-\mu_{\mathrm{s}} / \sigma_{\mathrm{s}}+\rho_{t s} \mu_{t} / \sigma_{t}\right) /\left(1-\rho_{t s}\right)^{1 / 2} .
\end{aligned}
$$

Substituting $t=\left(\mathrm{T}-\mu_{t}\right) / \sigma_{t}$ and $\mathrm{S}=\left(\mathrm{S}-\mu_{\mathrm{S}}\right) / \sigma_{\mathrm{S}}$ into (1) yields,

$$
E(T \mid T>0, \quad S \leq 0)=\mu_{t}+\sigma_{t} G / F
$$

where $G$ denotes the right hand side of $(1) . E(T \mid T>0, S \leq 0)$ is the mean average donation for the regions with type 1 displacement and is used as an estimate of the donation received by households having this type of displacement.

Let the potential number of recipient households be $N_{r}$, and let $F_{h}$ be the proportion of households with type 1 displacement. The total displacement for all type 1 households is,

$$
\left(N_{r} F_{h}\right) \cdot E(T \mid T>0, S \leq 0)=N_{r} F_{h}\left[\mu_{t}+\sigma_{t} G / F\right]
$$

The proportion of type 1 households can be estimated from a variety of sources, for example, field workers in the distribution areas. Alternatively, an estimate of $F_{h}$ may be obtained using an Edgeworth expansion (1907,1917). This 
expansion provides an approximation to an arbitrary density function given some general regularity conditions. It is illustrated by Mardia (1970), Lee (1982), and Pretorius (1930). Its use is discussed in section 3.

\subsection{Households with Donations that Exceed Their Prior Consumption: Type 2 Displacement}

Type 2 displacement occurs when the donation equals or exceeds prior consumption. In this case, the displaced commercial sales equal prior consumption.

Define the standardized random variable $c_{0}=\left(C_{0}-\mu_{0}\right) / \sigma_{0}$ where $\mu_{0}$ and $\sigma_{0}$ are, respectively, the mean and standard deviation of $C_{0}$. Denote the correlation coefficient between $\left(c_{0}, s\right)$ as $\rho_{\text {cos }}$. A positive correlation coefficient implies that households with the largest prior consumption get the largest donations. A negative correlation implies that these households get the smallest donations.

Using Rosenbaum again, the mean average prior consumption for regions in which the average donation exceeds the average prior consumption is,

$$
E\left(C_{O} \mid C_{O}>0, S>0\right)=\mu_{O}+\sigma_{O} H / F^{\prime}
$$

where $\mathrm{H}=\phi(\mathrm{h})\left(1-\Phi\left(\mathrm{k} x^{2}\right)\right)+\rho_{\cos } \phi(\mathrm{k})\left(1-\Phi\left(\mathrm{h} \dot{x}^{\mathrm{x}}\right)\right)$, and

$$
\begin{aligned}
& \mathrm{F}^{\prime}=\operatorname{Prob}\left(c_{0}>-\mu_{0} / \sigma_{0}, \mathrm{~s}>-\mu_{\mathrm{S}} / \sigma_{\mathrm{S}}\right) \\
& \mathrm{h}=-\mu_{0} / \sigma_{0}, \\
& \mathrm{~h}^{*}=\left(-\mu_{0} / \sigma_{0}+\rho_{\cos } \mu_{\mathrm{S}} / \sigma_{\mathrm{S}}\right) /\left(1-\rho^{2} \cos \right)^{1 / 2}, \\
& \mathrm{k}=-\mu_{\mathrm{S}} / \sigma_{\mathrm{S}}, \\
& \mathrm{k}^{*}=\left(-\mu_{\mathrm{S}} / \sigma_{\mathrm{S}}+\rho_{\cos } \mu_{\mathrm{O}} / \sigma_{0}\right) /\left(1-\rho^{2} \cos \right)^{1 / 2} .
\end{aligned}
$$

Equation (4) is an estimate of the displacement associated with a household with a positive surplus. Multiplying this estimate by the number of type 2 households gives an estimate of the total displacement for these households.

$$
\left(N_{r} F_{h}^{\prime}\right) \cdot E\left(C_{O} \mid C_{O}>0, S>0\right)=N_{r} F_{h}{ }^{\prime}\left[\mu_{O}+\sigma_{O} H\left(\rho_{C O S}\right) / F^{\prime}\right]
$$

where $F_{h}{ }^{\prime}$ is the proportion of households that have positive prior consumption and a positive surplus which is estimated using an Edgeworth expansion.

\subsection{The Impact of Donations on Consumption}

Next, the effect of the commodity donation program on consumption is developed. Unlike displacement, no distinction is made between different types of households.

Define the average consumption concurrent with the program to be $C$. Write the standardized random variable as $c=\left(C-\mu_{C}\right) / \sigma_{C}$. Denote the 
correlation coefficient between $(c, t)$ as $\rho_{c t}$. The impact of both a lower price and a higher income associated with the donations are reflected in this coefficient.

The mean standardized average consumption given a positive average donations is,

$$
E\left(c \mid t>-\mu_{t} / \sigma_{t}\right)=\rho_{c t} \phi\left(-\mu_{t} / \sigma_{t}\right) /\left(1-\Phi\left(-\mu_{t} / \sigma_{t}\right)\right) .
$$

Substituting for $c$ and $t$ gives,

$$
E(C \mid T>0)=\mu_{C}+\rho_{C t} \sigma_{C} \phi\left(-\mu_{t} / \sigma_{t}\right) /\left(1-\Phi\left(-\mu_{t} / \sigma_{t}\right)\right) .
$$

The difference between the mean average consumption with the program and without it is taken as a measure of the program's impact on the consumption of recipients.

$$
\begin{aligned}
\mathrm{E}(\mathrm{C} \mid \mathrm{T}>0)-\mathrm{E}(\mathrm{C} \mid \mathrm{T}=0) & =\rho_{C t} \sigma_{C} \phi\left(-\mu_{t} / \sigma_{t}\right) /\left(1-\Phi\left(-\mu_{t} / \sigma_{t}\right)\right)+\rho_{C t} \sigma_{C} \mu_{t} / \sigma_{t} \\
& =\rho_{C t} \sigma_{C}\left[\phi\left(-\mu_{t} / \sigma_{t}\right) /\left(1-\Phi\left(-\mu_{t} / \sigma_{t}\right)\right)+\mu_{t} / \sigma_{t}\right] .
\end{aligned}
$$

The sign of ( 8 ) is determined by the correlation coefficient between ( $c, t)$. Since donations are non-negative, the condition that the average donation is zero is equivalent to the case in which no donations are made to any household. Equation (8), therefore, measures the impact of the program relative to the mean average consumption when the average donation is zero and is a measure of the effectiveness of the program at affecting consumption.

3. Calculating the Displacement and Consumption Effects of the Temporary Emergency Food Assistance Program (TEFAP)

Data from The 1986 Survey of TEFAP Recipients were used to calculate the displacement and the consumption effects of TEFAP cheese donations. To implement the procedure, a total of 42 systematic random samples consisting of 40 households each were generated from 1680 usable observations in the TEFAP survey. The mean values of the 42 random samples constituted the data used in this illustration. Summary statistics for the revelant variables calculated from the 42 observations are reported in Table 1 . These data are similar to aggregate data that generally would be available to evaluate a commodity distribution program, for example, data on the average response by states.

\subsection{Displacement Associated with Households Whose Donations Exceed Their Prior Consumption: Type 2 Displacement}

To calculated the mean average prior consumption for type 2 displacement (4) was calculated using an iterative method suggested by Rosenbaum. The method starts with initial values of the population moments, $\mu_{0}, \sigma_{0}, \rho_{c o s}, \mu_{S}, \sigma_{S}$. These values were used to calculate standardized moments of the truncated distribution. These sample moments, in turn, give 
rise to new estimates of the population moments, and the iteration continues until the sample moments are stable. Using this procedure $E\left(C_{0} \mid C_{0}>0, S>0\right)$ was calculated to be $2.44 \mathrm{lbs} /$ month.

The proportion of households in the TEFAP population with Type 2 displacement was calculated using a bivariate Edgeworth expansion. By assumption the required moments of the household distribution are unknown but were estimated from the joint distribution of the standardized means $\left(c_{0}, s\right)$ using the following formula.

$$
\begin{aligned}
& \bar{\mu}_{2}=\mu_{2} /(\mathrm{n})^{1 / 2} \\
& \bar{\mu}_{3}=\mu_{3} /(\mathrm{n})^{1 / 2} \\
& \bar{\mu}_{4}=\mu_{4} / \mathrm{n}+3(\mathrm{n}-1) / \mathrm{n}
\end{aligned}
$$

$$
\begin{aligned}
& \bar{\mu}_{11}=\mu_{11} \\
& \bar{\mu}_{12}=\mu_{12} / \mathrm{n}^{1 / 2} \\
& \bar{\mu}_{22}=\mu_{22} / \mathrm{n}+(\mathrm{n}-1) / \mathrm{n}\left[1+2 \mu_{11}{ }^{2}\right] \\
& \bar{\mu}_{13}=\mu_{13} / \mathrm{n}+3 \mu_{11}(\mathrm{n}-1) / \mathrm{n}
\end{aligned}
$$

where the bar indicates a moment from the distribution of $\left(c_{0}, s\right)$, and $n=42$ is the number of regions. The relationships in (9) are symmetric in their indices. If the numbers of households in the regions differ the above formula need to be adjusted. The bivariate Edgeworth expansion expressed in terms of the moments of the household distribution is given by Pretorius (1930) and discussed by Mardia (1970) and Lee (1982).

From this expansion type 2 households were calculated to be $58.1 \%$ of the population. This was close to the actual $56.5 \%$ obtained from the survey. Using the generally accepted estimate of five million TEFAP households in 1986, the annual displacement of commercial cheese sales attributed to households with type 2 displacement was calculated to be 83.32 million pounds.

\subsection{Displacement Associate With Households Whose Donations are Less Than Their Prior Consumption: Type 1 Displacement}

The TEFAP survey collected information only from households that received donated cheese. Since the average donation was positive for each region, the double truncation in (3) was simplified to a single truncation on $S$. Strictly speaking this is not correct since the underlying normal distribution of the average donations runs from plus to minus infinity. However, the results using a double truncation are no different from those reported below.

The mean donation for regions in which the average donation is less than or equal to the average prior consumptions is,

$$
E(T \mid S \leq 0)=\mu_{t}-\rho_{t S} \sigma_{t} \phi\left(-\mu_{S} / \sigma_{S}\right) / \Phi\left(-\mu_{S} / \sigma_{S}\right)
$$

The mean average donation using (10) was 2.10 pounds per month.

The proportion of households with type 1 displacement was estimated with the univariate Edgeworth expansion. This expansion requires moments of the generally non-normal household distribution. These moments were estimated using (9). The univariate Edgeworth expansion is given by Pretorius (1930). 
Type 1 households were calculated to be $25.2 \%$ of the total households, nearly identical to the actual value of $26.3 \%$. Assuming five million TEFAP households, the above estimates imply that type 1 households were associated with an annual displacement of commercial cheese sales equal to 31.75 million pounds.

Displaced sales for both types of households totalled 115.07 million pounds. Based on total TEFAP donations of 410 million pounds in 1986 this implies a displacement rate of $28 \%$. This means that $28 \%$ of TEFAP donations replaced sales of cheese by recipients that would have occurred without the program. Table 2 summarizes the results for both types of displacement.

A displacement rate of $28 \%$ falls between the rates previously estimated with different methods. The displacement rate for cheese calculated from time series regression analysis is $45 \%$; for cross section regression $15 \%$, and a rate of $35 \%$ is reported using The Survey of TEFAP Recipients. However, the definition of displacement used in these studies is not the same as the one used here, and, therefore, it is inappropriate to compare the rates. The definition of displacement used in previous studies defined displacement with respect to current consumption. The reasons for using prior consumption instead of current consumption in defining displacement were discussed at the beginning of section 2 .

\subsection{The Consumption Effect of TEFAP}

The impact of the TEFAP program on the mean consumption of cheese is measured by ( 8$)$. Since all households in the survey received a donation, $E\left(t \mid t>-\mu_{t} / \sigma_{t}\right)=0$. Accordingly, (8) becomes

$$
E(C \mid T>0)-E(C \mid T=0)=\rho_{C t} \sigma_{C} \mu_{t} / \sigma_{t}
$$

Using this expression it was estimated that TEFAP increased the mean average cheese consumption by $2.87 \mathrm{lbs}$. per month per household, or on average, $62.2 \%$ of TEFAP donations in 1986 resulted in new cheese consumption. This number needs qualification. First, this result applies only to the average consumption of recipient households, not to all households or even all TEFAP eligible households. Second, consumption was not measured directly in the survey. Instead, starting with the level of TEFAP donations various adjustments were made to arrive at current consumption. Not surprisingly, there was a large correlation between donations and current consumption which implied a large impact on consumption by TEFAP donations.

\section{Summary}

This paper illustrated a method for calculating the magnitude of both the displaced commercial sales and the additional consumption caused by a commodity distribution program. This procedure requires only observations on average donation size, average consumption, etc. for samples of recipients or eligible households. Compared to the methods that have been used it is easier and cheaper to implement. 
The method was illustrated using 1986 data from the TEFAP survey. It was calculated that $28.8 \%$ of TEFAP donations displaced commercial sales of cheese, and that $62.2 \%$ resulted in increased cheese consumption. These two numbers do not add to $100 \%$ because displacement was based on prior consumption and the consumption effect was based on current consumption. Estimated displacement was accurate to within $1 \%$ of its actual level. However, the measurement of current consumption in the TEFAP survey implies that the additional consumption caused by TEFAP is overestimated. 
Table 1: Sample Statistics for the Average Monthly Household Prior Consumption, Donation, and Surplus over Regions

\begin{tabular}{|c|c|c|c|c|c|c|c|}
\hline Variable & mean & $\begin{array}{l}\text { standard } \\
\text { deviation }\end{array}$ & skewness ${ }^{a}$ & kurtosis $^{a}$ & $\rho_{\cos }$ & $\rho_{c t}$ & $\rho_{\text {st }}$ \\
\hline $\mathrm{C}_{0}$ & $2.291 \mathrm{bs}$. & 0.40 & -0.04 & -0.52 & .47 & & \\
\hline $\mathrm{C}$ & 4.431bs. & 0.59 & -0.18 & 3.08 & & .97 & \\
\hline $\mathrm{T}$ & 4.611bs. & 0.85 & 0.38 & 2.78 & & .97 & .90 \\
\hline S & $2.201 \mathrm{bs}$. & 0.54 & 0.34 & 2.32 & .47 & & .90 \\
\hline
\end{tabular}

a. Values were obtain from PROC PLOT using SAS

Table 2: 1986 Actual and Calculated Displacement by Type.

Type 1 Displacement: Donations Less Than Prior Consumption
Type 2 Displacement: Prior Consumption Greater than Donations
Monthly
Displacement per Household

$\begin{array}{lll}\text { Actual } & 2.20 \mathrm{lbs} . & 2.39 \mathrm{lbs} . \\ \text { Calculated } & 2.10 \mathrm{lbs} & 2.44 \mathrm{lbs} .\end{array}$
Total Annual
Displacement ${ }^{a}$ Actual $34.72 \mathrm{mil} .1 \mathrm{bs}$
Calculated
$81.02 \mathrm{mil} .1 \mathrm{~b}$ 85.06
Proportion
Actual
Calculated
0.262
0.252
0.565
0.581

a. An estimated 5 million recipient TEFAP households in 1986 was assumed. 
Blaylock, James R. and William N. Blisard (1988) Effects of Advertising on Demand for Cheese. USDA-ERS, Technical Bulletin No. 1752

Edgeworth, F.Y. (1907) "On the Representation of a Statistical Frequency by a Series." Journal of the Royal Statistical Society, 70, 102-06.

(1917) "On the Mathematical Representation of Statistical Data." Journal of the Royal Statistical Society, $80,266-88$.

Lee, Lung-Fei (1982) "Some Approaches to the Correction of Selectivity Bias", Review of Economic Studies, 49, 355-372.

Mardia, K.V. (1970) Families of Bivariate Distributions. (Connecticut: Hafner Pub. Co.)

Pretorius, S.J., (1930) "Skew Bivariate Frequency Surfaces, Examined in the Light of Numerical Illustrations", Biometrika, 22, 109-223.

Rosenbaum, S. (1961). "Moments of a Truncated Bivariate Normal Distribution". Journal of the Royal Statistical Society (Ser.B), 23(2):405-8.

USDA-Food and Nutrition Service. (1987) "Effects of The Temporary Emergency Food Assistance Program (TEFAP) on Displacement of Commercial Sales-1987

Report to Congress". August. . (1986) "The Survey of TEFAP Recipients". November.

Zellner, James A and Larry G Traub (1987). "In-kind Food Assistance and Consumer Food Choice" The Journal of Consumer Affaires, Vol. 21, No. 2 pp. $221-37$. 